\title{
Genetic Differences in Social Behavior: Relation to Natural Killer Cell Function and Susceptibility to Tumor Development
}

John M. Petitto, M.D., Donald T. Lysle, Ph.D., Jean-Louis Gariepy, Ph.D., Patricia H. Clubb, B.A., Robert B. Cairns, Ph.D., and Mark H. Lewis, Ph.D.

The hypothesis that certain heritable personality traits would correlate with increased vulnerability to tumor development and reduced natural killer (NK) cell function was tested in mice selectively bred for high and low levels of aggression. This selection program produces a line of mice that fail to exhibit species typical, isolation-induced aggression, but appear socially inhibited in response to a novel partner mouse. All socially inhibited mice developed 3-methylcholanthrene-induced tumors compared with only $44 \%$ of the aggressive mice. Basal NK activity was also significantly lower among socially inhibited mice.
Conversely, there were no line differences in NK activity between the aggressive line and nonselected, socially isolated mice, consistent with other unidirectional outcomes of this selective breeding program. No significant line differences were present for nonsocial measures of emotional reactivity (e.g., fearfulness) or serum corticosterone levels. These findings support the hypothesis that social "traits" may be related to immune function and tumor susceptibility.

[Neuropsychopharmacology 8:35-43, 1993]
KEY WORDS: Psychoneuroimmunology; Aggression; Social inhibition; Natural killer cells; Selective breeding; Social behavior

Much of the psychoneuroimmunology literature has focused on understanding how various nonsocial and sodal "states" such as bereavement and depression can alter immune function (for reviews see Tecoma and Huey 1984; Calabrese et al. 1987; Stein et al. 1991). In particular, considerable attention has been given to the effects of various experimental stressors on immune measures in animals (for reviews see Ader 1981; Ader and Cohen 1991). The notion that certain heritable per-

From the Departments of Psychiatry and Neuroscience, University of Florida, Gainesville, FL (JMP, MHL), and the Department of Psychology (DTL, J-LG, PHC, RBC), University of North Carolina at Chapel Hill, North Carolina.

Address correspondence to Dr. John M. Petitto, Department of Psychiatry, Box 100256, M-335, University of Florida, Gainesville, FL 32610-0256.

Received September 9, 1991; revised January 15, 1992; accepted January 28, 1992. sonality "traits" may render individuals more vulnerable to some immune-related disease states, in particular cancer, has intrigued clinicians for many years. Despite considerable theorizing about the relationship of personality variables to disease susceptibility (Hagnell 1966; Fox 1978; Wellisch and Yager 1983), little empirical data relate immune function to genetically determined individual differences in behavior that are stable across development.

Selective breeding, a powerful research strategy, has been used to study how genetic influences may interact with developmental and experiential factors to produce individual differences. For example, selective breeding has provided a basis for investigating neurobiological mechanisms that underlie individual differences such as alcohol sensitivity, open-fieldactivity, and emotionality (Fuller and Thompson 1978). Cairns and colleagues (1983) have selectively bred Institute for Cancer Research (ICR) mice, an outbred strain which has been widely used in cancer research, for high and low levels of aggression. Selection effects appeared rapidly, 
with robust line differences in aggression or attack obtained by the fourth $\left(S_{4}\right)$ generation. Although the breeding program was aimed at developing lines with both high and low aggressive characteristics, relatively little change in isolation-induced attack across generations has been observed in the high aggressive (NC900) line relative to the foundational stock and to nonselected, randomly bred mice (NC600) derived from the same ICR stock. Conversely, considerable decreases in attack were observed across generations of the low aggressive (NC100) line (Gariepy et al. 1988). Thus, this work has led to a line of mice (NC100) that fail to exhibit the isolation-induced aggression expected of this mouse strain.

Rather than being aggressive, isolated NC100 mice become inhibited in response to social contact, exhibiting immobility or freezing when confronted with an unselected male ICR group-housed partner mouse. Crossgenerational analysis of the social behavior of NC100 animals indicates a direct parallel between the emergence of the freezing response and the reductions observed in aggressive behavior (Gariepy et al. 1988). By contrast, and consistent with the unidirectional selective breeding effects, the tendency to freeze in the NC900 generations remained low and did not deviate markedly from the $S_{0}$ generation. Recent studies from our lab indicate that mesolimbic dopaminergic pathways may play an important role in mediating the marked social inhibition observed in the NC100 mouse line (Lewis et al. 1992).

We sought to test the hypothesis that the genetic differences in the social behavior observed in NC100 mice would correlate with increased vulnerability to tumor development in vivo(Stutman 1973; Hewitt 1978). Since natural killer (NK) cells have been suggested to play a role in immune surveillance against neoplastic growth, we also predicted that the NC100 mice would exhibit lower levels of functional NK cytolytic activity against tumor target cells in vitro. These measures were obtained from animals raised in social isolation following weaning, the condition under which the robust behavioral line differences are observed. Moreover, this provided the advantage of eliminating the confounding effects of social experience and ensured uniformity in individual experience.

Finally, we sought to confirm that such line differences in NK cell function and tumor susceptibility are specifically related to selection for genetic differences in response to social interactions rather than transsituational fearfulness or emotional reactivity. To this end, we compared the selected mouse lines on measures of social behavior in a dyadic test, measures of nonsocial behavior in a test of reactivity to tactile stimulation, and in an elevated plus-maze. The elevated plus-maze test has been shown to be a reliable measure of the level of fearfulness or emotional response to novelty in mice
(Lister, 1987). It was expected that only measures obtained in the social stimulation test would differentiate the lines.

\section{METHODS}

\section{Selection and Rearing}

Male attack behavior was the sole criterion used in selectively breeding ICR mice. The same criterion was employed in successive generations; sisters of the selected males provided the mating partners for other males within each selected line. Brother-sister mating was not permitted. Earlier reports have detailed the breeding criteria and outcomes over successive early and late generations (Cairns et al. 1983; Gariepy et al. 1988). In each generation, male mice were weaned at 21 days of age and then reared in individual cages. They were tested at 45 days of age for aggressive behavior in social interaction tests (this has been the standard test age for all previous generations). They had no social contact other than exposure to the noises and odors produced in the colony room. The NC600 mice that served as test partners were reared, after weaning, in groups of five males. The NC600 test partners were also ICR mice, except that these partners were not selectively bred. Details of these methods have been described previously (Cairns et al. 1983; Gariepy et al. 1988).

All experiments in the present investigation were conducted using socially isolated mice of generations $S_{21}$ and $S_{22}$ of the selection program. For the tumor development and NK activity experiments, untested, socially isolated male littermates of animals tested in the behavioral paradigms were used. This was done to eliminate confounding effects of such experience (e.g., outcome of fighting) on these dependent measures.

\section{Nonsocial Behavior}

Reactivity to tactile stimulation test. A total of 53 adult male mice ( $28 \mathrm{NC} 100$ and $25 \mathrm{NC} 900$ ) were studied in the 21st generation of the selection program at $45 \pm 2$ days of age. Mice were tested for reactivity to tactile stimulation (RTS) for 2 minutes. Each animal was placed in a plexiglass cage with an ebonite floor floated on four light-weight springs. After 30 seconds' habituation, the mouse was tapped lightly on its flank with a cotton swab. Six stimulations were delivered on a 15second variable interval schedule. The tests were conducted during the dark cycle 3 to 6 hours after the offset of lights in the reversed day-night cycles. All observations were conducted in a dimly lit laboratory room.

The RTS tests yield a measure of nonsocial reactivity rated on a five-point scale. A score of 1 was given if the animal showed no apparent reaction to stimulation. Higher scores were given when the animal reacted 
(e.g., within 0.5 second) with any combination of reflexive kicks, vocalizations, or jumps. The mean of the six reactions was the animal's RTS score. Interobserver reliability for this measure has been checked periodically and ranged from $r=0.93$ to $r=0.98$ throughout the testing periods, with no reliable differences in interobserver means.

Eleoated plus-maze test. A total of 37 socially isolated male mice (20 NC100 and 17 NC900) were studied in the 21st generation of the selection program. The plusmaze test was conducted as previously described (Lister 1987). Briefly, the plus-maze is composed of an elevated $(38.5-\mathrm{cm})$ central platform $(5 \mathrm{~cm} \times 5 \mathrm{~cm})$ surrounded by four arms $90^{\circ}$ apart, thus forming the plus sign configuration. The two open arms $(30 \mathrm{~cm} \times 5 \mathrm{~cm})$ are $180^{\circ}$ apart, as are the two closed arms $(30 \mathrm{~cm} \times 5 \mathrm{~cm})$. The far end of each closed arm has side walls $(15 \times 5$ $\mathrm{cm})$ which are $14.5 \mathrm{~cm}$ high. Allcomponents of the maze are made of black plexiglass.

The mouse was placed in the center of the central platform, and the 5-minute test session began when it entered one of the four arms. Entry into an arm was counted when all four legs were on the arm and scored using a lap-top computer. The variables assessed included the total number of crossings into the open and closed arms, the percentage of time spent in the open and closed arms, and the latency to initiate the 5-minute test session by entering an arm from the central platform. Testing was performed under dim lighting.

\section{Social Behavior}

Social interaction test. On the day following the RTS test, 53 socially isolated adult male mice ( $28 \mathrm{NC} 100$ and $25 \mathrm{NC} 900$ ) were studied in generation $S_{21}$. Thirty animals from generation $S_{22}$ were studied (15 NC100 and 15 NC900). Each mouse was placed on one side of the test cage, and a same-age, group-reared male of the unselected line (NC600) was placed on the other side. Each animal had been habituated to the test cage for 10 minutes on the previous day. The test cage was constructed of plexiglass $(20 \times 21 \times 31 \mathrm{~cm})$ and had a removable sheet-metal panel which divided the compartment in two separate chambers. After 5 minutes, the panel was removed, and interactions between the subject and the partner were scored for 10 minutes. After testing, both animals were weighed and then returned to their home cages.

In the social interaction test, both the behavior of the test animal as well as that of the partner mouse was scored. This continuous scoring method allowed us to code (1) the behavior of the test animal towards its partner, including initiation of behaviors and the responses to those behaviors, and (2) the sequence in which the social events occurred, including interactions between animals and within-animal autocorrelated behaviors and states (Cairns and Nakelski 1971; Cairns and Scholz 1973). In the several generations where these behavioral categories have been used, interobserver agreement has always exceeded $90 \%$. All behavioral procedures were conducted with experimenters uninformed as to which selected lines were represented in the tests.

\section{Tumor Induction}

Tumors were induced in socially isolated NC900 $(n=$ $9)$ and NC100 $(n=10)$ mice of generation $S_{21}$ using the carcinogen 3-methylcholanthrene (3-MC; Sigma Chemical Co.) (Stutman 1973; Hewitt 1978; Petitto et al. 1990). 3-Methylcholanthrene was dissolved in corn oil at a final concentration of $10 \mathrm{mg} / \mathrm{ml}(37 \mu \mathrm{mol} / \mathrm{ml})$ and administered as a single intramuscular injection $(0.2 \mathrm{ml}$ volume) in the right hindlimb.

Mice were examined at weekly intervals after 3-MC injection for evidence of palpable tumors at the injection site. Both the tumor incidence and latency period were noted. It was determined a priori that when any of the experimental subjects evidenced a substantial tumor burden (e.g., greater then $3 \mathrm{~g}$ ) all of the mice would be killed simultaneously and tumor weights quantified. Tumors were excised and weighed and an autopsy was performed for visual or palpable metastases.

\section{Natural Killer Cell Function}

The splenic NK cell activity of socially isolated animals ( $n=8$ animals/group) of the selected NC100 and NC900 mouse lines, as well as nonselected NC600 mice, was examined in generation $S_{22}$. All animals were 8 weeks of age at the time of testing. In alternating order by subject group, each animal was killed by cervical dislocation at approximately 0700 . Spleens were immediately removed, and a single cell suspension of each mouse's spleen was prepared by gently pressing the tissue between the ends of sterile frosted microscope slides in supplemented RPMI enriched with 10\% FCS. Each mouse's splenocytes were counted using a (CelltrakII; NOVA) cell analyzer and adjusted to $5 \times 10^{6} \mathrm{cells} / \mathrm{ml}$.

Splenic leukocytes were tested for NK cytotoxic activity by using a ${ }^{51} \mathrm{Cr}$ release assay. The murine $\mathrm{T}$-cell lymphoma tumor line, YAC-1, was maintained in supplemented RPMI plus $10 \%$ FCS in a humidified $\mathrm{CO}_{2}$ incubator ( $95 \%$ air $/ 5 \% \mathrm{CO}_{2}$ atmospheres). On the day of the assay, YAC-1 targets were prepared by labeling them for 70 minutes with $200 \mu \mathrm{Ci}$ sodium chromate-51 $\left(\left[{ }^{51} \mathrm{Cr}\right] \mathrm{Na}_{2} \mathrm{CrO}_{4}\right.$; Dupont-New England Nuclear). The YAC-1 cells were then washed three times to remove exogenous ${ }^{51} \mathrm{Cr}$. Splenic effector cells from each mouse were added to flat-bottom microtiter plates (Costar 3595) in triplicate at $20,10,5$, and $2.5 \times 10^{5}$ cells/well. Labeled targets were diluted and plated at $1 \times 10^{4}$ cells/well, thus yielding effector:target $(\mathrm{E}: \mathrm{T})$ cell ratios 
of 200:1, 100:1, 50:1, and 25:1. Control wells containing only labeled targets were also plated to determine spontaneous and maximum release. Microtiter plates were centrifuged at $600 \mathrm{rpm}$ for 4 minutes and incubated for 4.5 hours at $37^{\circ} \mathrm{C}$. Following incubation, the supernatant was harvested using a Titertek multichannel pipette. The amount of ${ }^{51} \mathrm{Cr}$ released in the supernatant of each well was counted using a LKB gamma counter (model 1271; CliniGamma) using the equation below:

$$
\begin{gathered}
\text { \% Lysis }= \\
\frac{\text { Exp. cpm }- \text { Spontaneous cpm }}{\text { Maximum cpm }- \text { Spontaneous cpm }} \times 100 .
\end{gathered}
$$

Exp. cpm was defined as the counts released into the medium by target cells assayed with effector cells. Maximum cpm was defined as the counts released by lysed target cells (without effector cells present) following the addition of $10 \%$ trichloroacetic acid. Spontaneous cpm was defined as the counts released by target cells incubated alone (without effector cells present).

\section{Serum Corticosterone Assays}

Circulating corticosterone levels were measured in 45 adult male mice (23 NC100 and 22 NC900) of the $S_{21}$ generation. Truncal blood was collected in plastic centrifuge tubes and centrifuged for 20 minutes at $100 \mathrm{~g}$. Serum was then collected, immediately frozen, and stored at $-70^{\circ} \mathrm{C}$. All samples were thawed simultaneously and corticosterone determinations performed in the same assay using a highly specific radioimmunoassay kit (ICN Biomedicals).

\section{RESULTS}

\section{Social Behavior}

Dyadic test. Figure 1 shows the frequency of attack and freezing observed among generations $S_{21}$ and $S_{22}$. In both generations, aggressive (NC900) animals attacked the partner mouse significantly more often than did socially inhibited (NC100) animals [ $S_{21}: F(1,51)=$ 25.46, $p<0.001$; $S_{22}: F(1,28)=16.81, p<0.001$ ], with significantly reduced latency (data not shown). Conversely, NC100 mice exhibited more freezing in response to social stimulation than NC900 mice $\left[S_{21}\right.$ : $F(1,51)=19.94, p<0.001 ; F(1,28)=16.81, p<0.001]$. These results replicated the line differences observed in all previous generations following $S_{4}$, after which genetic selection effects have been robust (Cairns et al. 1983; Gariepy et al. 1988).

\section{Tumors}

Tumors first became palpable by 13 weeks posttreatment; all mice were killed during week 17 . There were

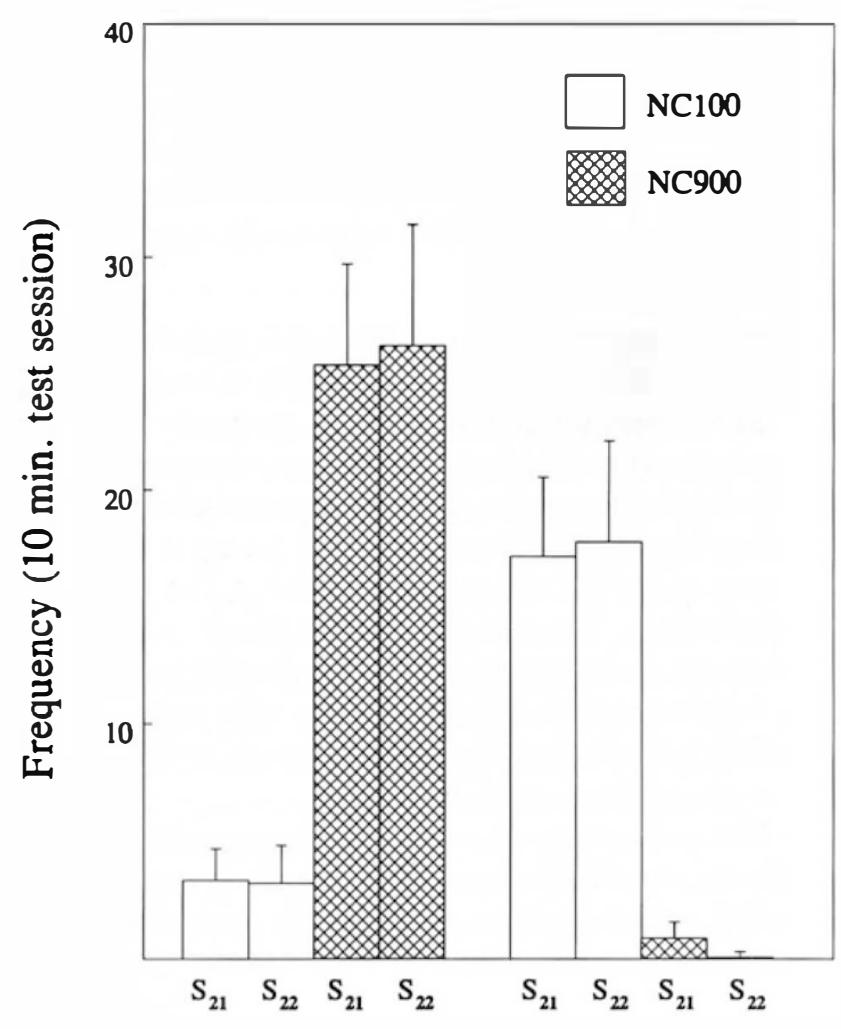

ATTACK FREEZING

Figure 1. Frequency of attack and freezing (mean \pm SEM) in the dyadic social interaction test for generations $S_{21}$ and $\mathrm{S}_{22}$ of the selective breeding program. In both generations, the aggressive (NC900) animals attacked the partner mouse significantly more often than did socially inhibited (NC100) animals. Conversely, on measures of freezing upon social stimulation, the socially inhibited (NC100) mice exhibited this response significantly more than aggressive (NC900) mice.

clear differences in the number of animals of each line that developed tumors, as well as line differences in tumor burden. As depicted in Figure 2, all NC100 mice ( $n=10$ ) had developed tumors by the time of sacrifice, whereas only 4 NC900 mice $(n=9)$ showed evidence of tumor development $\left[\chi^{2}(1,18)=4.95, p<0.05\right]$. In addition, NC100 mice showed greater tumor burden, with 3 animals having tumors weighing over three grams. None of the NC900 mice displayed tumors of this size. No clear line difference in the latency to develop tumors was apparent. Neoplastic growth was contained within the hind leg for all subjects with the exception of one NC100 animal, which showed evidence of growth extension into the vertebral column.

\section{Natural Killer Cell Activity}

Graded lysis of YAC-1 target cells by effector spleen cells was observed across the E:T ratios. The spontaneous ${ }^{51} \mathrm{Cr}$ release from target cells was less than $10 \%$ of max- 


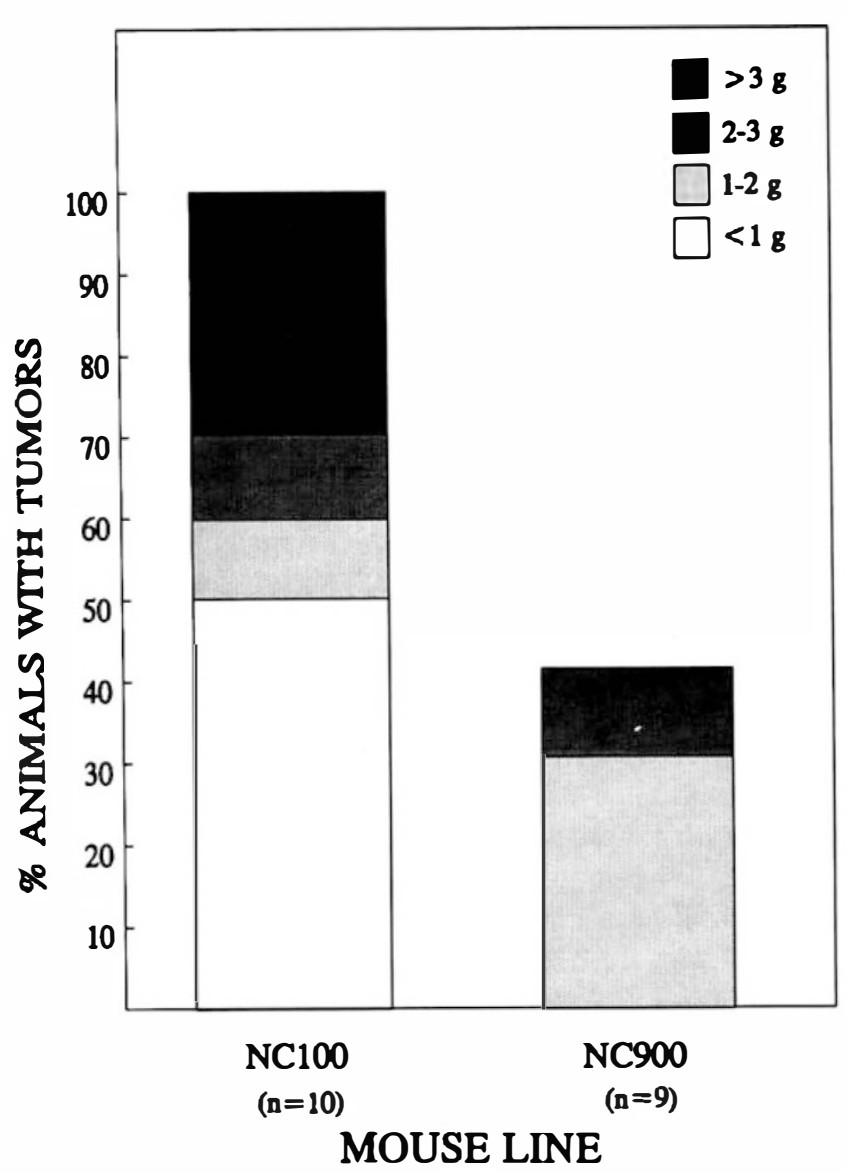

Figure 2. Mouse line differences in tumor development at week 17 following 3-methylcholanthrene injection in the right hindlimb. The stacked bars represent the percentage of tumorbearing mice in each selected line with tumors of a particular weight range. All of the socially inhibited (NC100) mice developed tumors, compared with only $44 \%$ of the aggressive (NC900) mice.

imum ${ }^{51} \mathrm{Cr}$ release. A two-factor repeated ANOVA [group(NC100, NC600, NC900) and E:T ratio] revealed significant main effects of group $[F(2,21)=4.69, p=$ $0.02]$, and $E: T$ ratio $[F(3,21)=42.9, p<0.00001]$ as well as a significant group by $\mathrm{E}: \mathrm{T}$ ratio interaction $[F(6,21)$ $=3.50, p=0.005$ ]. As shown in Figure 3, the level of splenic NK activity of NC100 mice was $75 \%$ (E:T ratio 200:1) to 100\% lower (E:T ratio 25:1) than that of NC900 mice across the four E:T ratios tested. Post hoc analyses (Scheffe's test) confirmed that these differences between the NC100 and NC900 selected lines were statistically significant $[F(1,14)=7.84, p<0.01]$, and that nonselected (NC600) mice also exhibited significantly greater splenic NK cytotoxic activity than NC100 animals $[F(1,14)=6.10, p<0.05]$. The NK activity of the NC900 line was not significantly different from that of NC600 mice $[F(1,14)=0.11, p=0.74]$. These selected mouse line differences have now been confirmed in three separate experiments (data not shown).

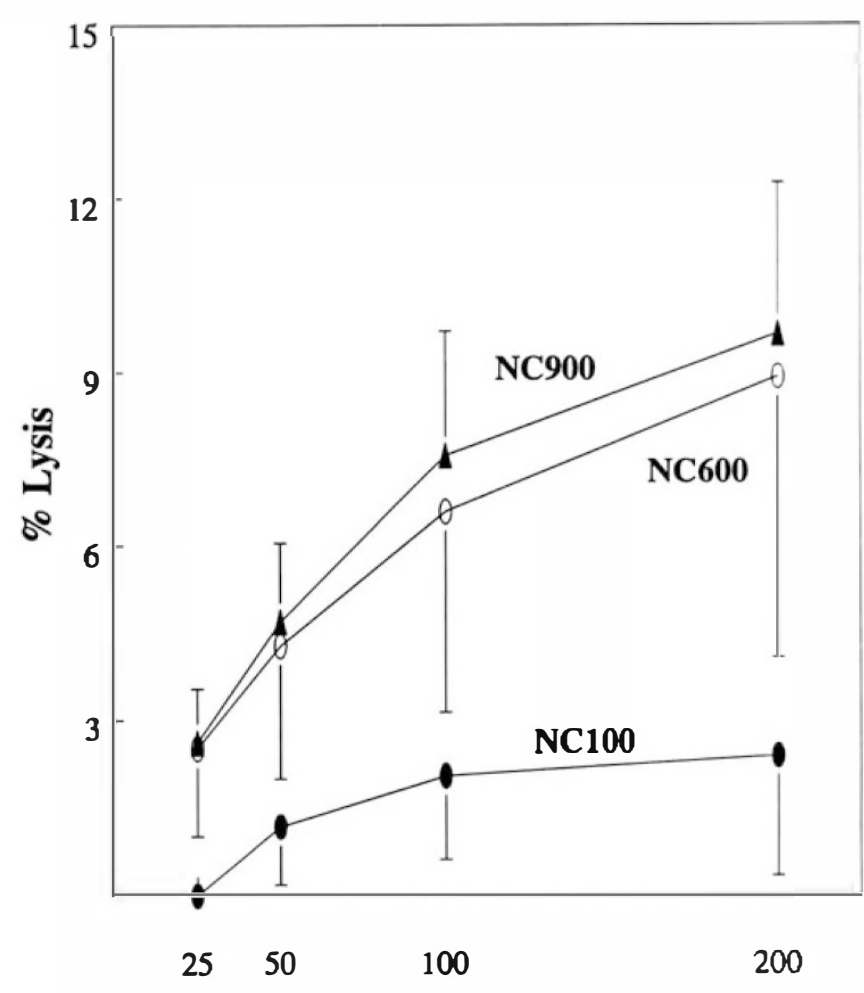

\section{Effector:Target Cell Ratio}

Figure 3. Comparison of splenic NK activity in socially inhibited (NC100), aggressive (NC900), and nonselected (NC600) mice. NK effector cells were tested against YAC-1 tumor target cells at E:T ratios of 200:1, 100:1, 50:1, and 25:1. Each point represents the mean \pm SEM for eight animals. Mice of the socially inhibited (NC100) line exhibited significantly reduced NK cytotoxic activity compared with mice of the aggressive line (NC900) and nonselected(NC600) mice. The NK activity of mice of the aggressive line (NC900) was not significantly different from that of nonselected (NC600) mice. These group differences have been replicated in three separate experiments in the $S_{24}$ generation (data not shown).

\section{Serum Corticosterone Levels}

As depicted in Figure 4, there was substantial variability in serum corticosterone concentrations among the NC100 and NC900 selected lines. These line differences in corticosterone levels were not statistically different $[t(1,43)=1.92, p=0.06)$.

\section{Nonsocial Behavior}

Reactivity to tactile stimulation test. None of the measures of response to nonsocial stimuli obtained in the RTS test differentiated the selected mouse lines. Mean scores of reactivity to tactile stimulation $[F(1,51)$ $=0.49, p=0.49]$, measures of defecation $[F(1,51)=$ $1.99, p=0.17]$, and urination $[F(1,51)=0.33, p=0.57]$ 


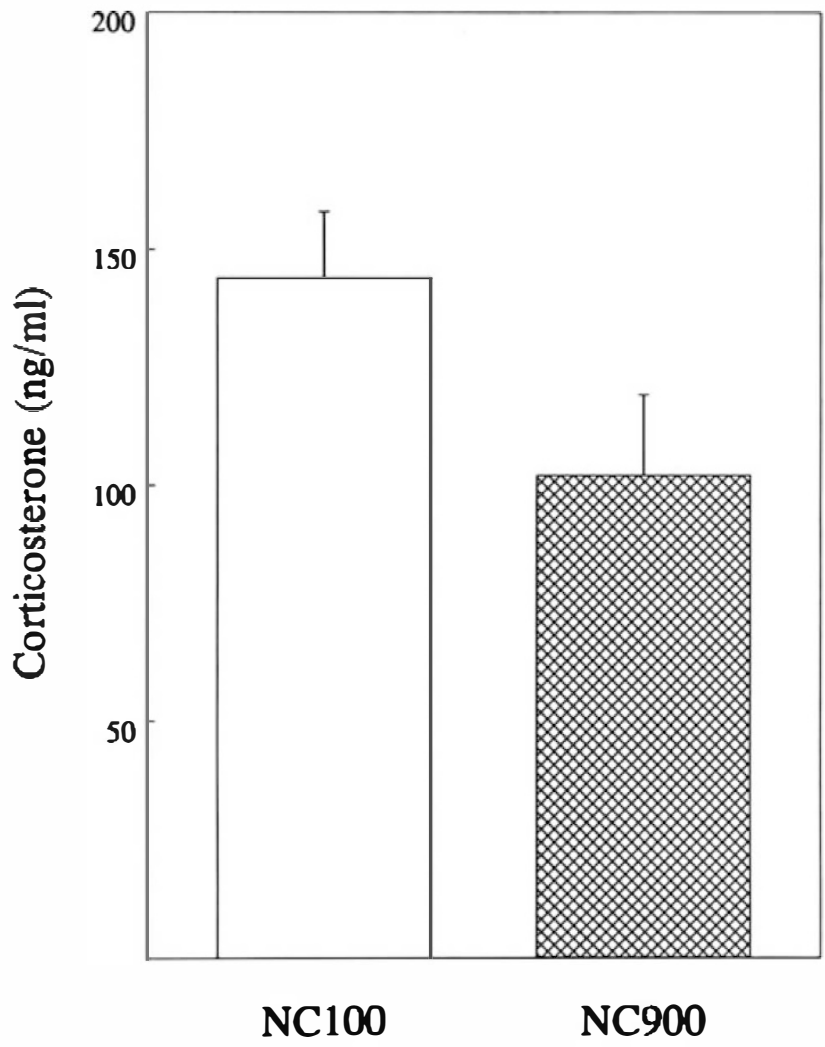

Figure 4. Baseline corticosterone levels (mean \pm SEM) of socially isolated mice of the aggressive (NC900) and socially inhibited (NC100) mouse lines. Differences in serum corticosterone concentrations were not found to be statistically different.

failed to show differences between mice of the NC100 and NC900 lines.

Plus maze. There were no differences between the NC100 and NC900 mouse lines in the elevated plusmaze behavior for time spent in the open arms $[F(1,34)$ $=1.2, p=0.28]$, total number of crossings $[F(1,34)=$ $1.1, p=0.30]$, or latency to first enter an arm from the central platform $[F(1,34)=1.3, p=0.27]$.

\section{DISCUSSION}

These results demonstrate that selective breeding for genetic differences in social behavior resulted in marked differences in tumor susceptibility and NK cell activity between the NC100 and NC900 mouse lines. Consistent with the hypothesis that the socially inhibited (NC100) line would be more vulnerable to tumor development, all of the NC100 mice tested developed tumors compared with only $44 \%$ of the aggressive (NC900) mice. Tumor burden among NC100 mice was also substantially greater than among NC900 mice. This latter finding is highlighted by the observation that while $30 \%$ of the NC100 mice had tumors that weighed more than three grams, no mouse of the NC900 line developed a tumor of this size.

NK cells are a heterogeneous subset of large granular lymphocytes that possess cytotoxic activity that is not restricted by the major histocompatibility complex. It has been suggested that these cells play a role in immune surveillance against neoplastic growth as well as microbial infection, and have more recently been shown to possess various immunoregulatory functions, including the production of lymphokines (Heberman and Ortaldo 1981; Trinchieri 1989). In addition to being more vulnerable to tumor development, the NC100 line also exhibited markedly reduced NK cytolytic activity against Y AC-1 tumor target cells in vitro compared to the NC900 mouse line. Levels of NK activity were the same among NC900 animals and randomly bred NC600 mice, but were substantially lower among NC100 mice. The line differences in NK activity mirrored the behavioral outcomes of the selective breeding program, where only the low aggressive line significantly departed from the foundational levels of attack and freezing behavior.

Inbred mouse strains classified as low NK responders have been shown to be more prone to various types of experimentally induced tumor development (Kiessling et al. 1975; Karre et al. 1980; Talmadge et al. 1980). The ICR foundational strain is a low-NK responding strain which has been reported to exhibit greater susceptibility to some types of cancer than common inbred strains such as C57/BL6 and DBA/2, which possess intermediate levels of NK activity (Evans et al. 1972; Hauschka and Mirand 1973; Kiessling and Wigzell 1979). In light of these strain differences, the very low levels of NK activity associated with the genetic selection performed on these ICR-derived mice may have contributed to the observed increased incidence of 3-MC-induced tumors in the NC100 line. Although natural immunity has been shown to be involved in 3-MCinduced tumor development (Stutman 1973; Stutman and Lattime 1981), the greater incidence of tumors in the NC100 line cannot be causally attributed to reduced NK cell function. It will be important to assess other immune parameters associated with tumor control (e.g., cytotoxic T cells, tumoricidal macrophages, lymphokine activated killer cells) to characterize further this mouse line difference in tumor susceptibility (Fidler and Poste 1982; Unanue and Benacerraf 1984; Rosenberg et al. 1986).

NK cytotoxic activity in mice is a complex phenotype that is under polygenetic control. Different gene loci appear to control NK cell number, lytic activity, and regulatory activity (Petryani et al. 1975; Clark et al. 1979; Kiessling and Wigzell 1979; Welsh 1988). Certain mutations have profound effects on NK cell function, and different inbred mouse strains exhibit wide variation 
in NK activity (Clark et al. 1981; Reynolds and Holden 1982; Kiessling and Wigzell 1979). Because inbreeding is proscribed in selective breeding (no sibling or cousin mating), those alleles not associated with the selected trait should assort randomly. Therefore, it is possible that the genetic selection for low levels of aggression may have coselected for the very low levels of functional NK activity evidenced by socially isolated NC100 mice. It is possible that the line differences in this immune parameter were magnified in the present case by the environmental experience of social isolation. However, since this environment was the same for all mice, the observed differences were clearly mediated by known differences in genetic background between the selected lines. How interactions between "traits" and "states" may alter NK cell function is poorly understood. In fact, the NC selected lines have been shown to exhibit a high degree of plasticity to experiential influences (e.g., variations in rearing conditions). Thus, it would not be surprising to discover in future experiments that the expression of genetic differences in aspects of immune function are also altered as a result of experiential input. Studies designed to examine experiential as well as mechanistic factors including flow cytometric determinations of NK cell types using specific NK cell monoclonal antibodies, NK cell responses to regulatory cell signals (e.g., IFN), and other components of immune system function (e.g., T cell-mediated IL-2 production) will be important parameters to investigate in future generations.

Although basic investigations suggest that several neural pathways (e.g., noradrenergic, GAbAergic) and neuroendocrine peptides (e.g., CRF, $\beta$-endorphin) may influence NK activity (Irwin et al. 1989; Petitto et al. 1989; Morley 1987; Solomon 1987), corticosterone has been the focus of particular attention as an important mediator of brain-immune interactions because of its link to both stress and immunity (for reviews see Ader 1981; Ader et al. 1991). Unlike the small degree of variability in NK activity evidenced by the selected mouse lines, baseline corticosterone levels exhibited substantial variability. While the NC100 mice evidenced clear reductions in NK activity compared to NC900 mice, baseline corticosterone levels did not clearly differentiate the lines. Hence, circulating corticosterone does not appear to be the principal mechanism responsible for the significantly reduced baseline level of NK cell activity among mice of the NC100 line. Recent studies from our lab suggest that selective differences in mesolimbic dopaminergic pathways may play an important role in mediating the marked social inhibition observed in the NC100 mouse line (Lewis et al. 1992). By regulating aspects of endocrine function as well as sympathetic neuronal activity in the periphery (e.g., spleen), limbic circuitry (e.g., amygdala, hippocampus, hypothalamus) appears to play a role in the CNS modulation of immune function (Felten and Felten 1987). Irwin et al. $(1988,1990)$ have demonstrated that CRF administered intracerebroventricularly produces reduced splenic NK cell activity in rodents by activating the sympathetic nervous system. Midbrain dopaminergic pathways are involved in modulating a number of neurotransmitters and neuropeptides in brain (LeMoal and Simon 1991). It is possible, for example, that mouse line differences in dopaminergic neurotransmission in the central amygdaloid nucleus may modulate preganglionic sympathetic autonomic neurons in the brainstem (Kilts et al. 1988), resulting in line differences in peripheral sympathetic tone and thus differences in splenic NK activity. Future investigations will examine whether these differences in central dopaminergic function may be mechanistically related to differences in NK cell activity.

The absence of line differences in response to nonsocial stimuli in the elevated plus-maze and RTS tests confirms that the robust difference in behavioral inhibition is not a manifestation of a more global difference in fearfulness or emotionality, but is evoked by social stimuli. While the majority of preclinical studies of the stressful "states" on immunity and disease processes have focused on nonsocial laboratory stressors (e.g., footshock), more naturalistic forms of social stress have also been shown to alter aspects of immunocompetence (for review see Bohus and Koolhaas 1991). For example, social confrontation may affect immune functions in rodents as well as other vertebrates (Faisal et al. 1989). Our data are the first to demonstrate directly that heritable social "traits" are correlated with NK cell function and cancer susceptibility. The literature of social behavior and immunity generally indicates that the interactions between these behavioral and immune processes are highly complex. Thus, greater understanding of how individual differences in social behavior (traits) influence state-related changes in immunity and related disease processes may have important mechanistic implications.

In conclusion, although there has been considerable theorizing about the relationship of personality variables to immune-related clinical disease states such as cancer, there are no prospective data or other substantive evidence supporting such a relationship. Despite recent advances in the field of psychoneuroimmunology, there are also few empirical data relating behavioral traits to immune system function and immune-related disease processes. By demonstrating that genetic selection for the low aggressive (NC100) mouse line resulted in reduced NK cytoxic activity and greater vulnerability to tumor development, these experiments support the hypothesis that stable individual differences in social behavior may be associated with 
differences in disease susceptibility and immune function. Integration of neurobiological and immunological findings using this mouse model may provide important information regarding mechanisms of brainimmune interactions.

\section{ACKNOWLEDGMENTS}

The authors thank Kim Maslonek and Dr. George Mason for technical assistance with immunological and endocrine assays, respectively. This work was supported by a Foundation of Hope grant and PHS grant MH45371.

\section{REFERENCES}

Ader R (ed) (1981): Psychoneuroimmunology. New York, Academic Press

Ader R, Felten DL, Cohen N (eds) (1991): Psychoneuroimmunology. New York, Academic Press

Bohus B, Koolhaas JM (1991): Psychoimmunology of social factors in rodents and other subprimate vertebrates. In Ader R, Felten DL, Cohen N (eds), Psychoneuroimmunology. New York, Academic Press, pp 807-830

Cairns RB, Nakelski JS (1971): On fighting in mice: Ontogenetic and experimental determinants. J Comp Physiol Psychol 74:354-364

Cairns RB, Scholz SD (1973): Fighting in mice: Dyadic escalation and what is learned. J Comp Physiol Psychol 85:540-550

Caims RB, MacCombie DJ, Hood KE (1983): A developmentalgenetic analysis of aggressive behavior. J Comp Psychol 97:69-89

Calabrese JR, Kling MA, Gold PW (1987): Alterations in immunocompetence during stress, bereavement, and depression: Focus on neuroendocrine regulation. Am J Psychiatry 144:1123-1134

Clark BA, Russell PH, Egghart M, Horton MA (1979): Characteristics and genetic control of NK-cell-mediated cytotoxicity acvtivated by naturally acquired infection in the mouse. Int J Cancer 24:688-699

Clark EA, Shultz LD, Pollack SB (1981): Mutations in mice that influence natural killer (NK) cell activity. Immunogenetics 12:601-613

Evans JT, Lutman G, Mittelman A (1972): The induction of multiple large bowel neoplasms in mice. J Med 87:1-3

Faisal M, Chiappelli F, Ahmed II, CooperEL, Weiner H (1989): Social confrontation "stress" in aggressive fish is associated with an endogenous opiod-mediated suppression of proliferative response to mitogens and nonspecific cytotoxicity. Brain Behav Immun 3:223-233

Felten DL, Felten SY (1987): Immune interactions with specific neural structures. Behav Immun 1:287-289

Fidler IJ, Poste J (1982): Macrophages and cancer metastasis. Adv Exp Med Biol 155:65-75

Fox BH (1978): Premorbid psychological factors as related to cancer incidence. Behav Med 1:45-63
Fuller JL, Thompson WR (1978): Foundations of behavior genetics. St. Louis, MO, Mosby

Gariepy J-L, Hood KE, Cairns RB (1988): A developmentalgenetic analysis of aggressive behavior in mice, III: Behavioral mediation by heightened reactivity or increased immobility? J Comp Psychol 102:392-399

Hagnell O (1966): The premorbid personality of persons who develop cancer in a total population investigated in 1947 and 1957. Ann NY Acad Sci 125:846-855

Hauschka TS, Mirand EA (1973): The "breeder: HA(ICR)" Swiss mouse, a multipurpose stock selected for fecundity. In GPMurphy (ed), Perspectives in Cancer Research and Treatment. New York, Liss, pp 319-331

Herberman RB, Ortaldo JR (1981): Natural killer cells: Their role in defenses against disease. Science (Wash, DC) 214:24-30

Hewitt HB (1978): The choice of animal tumors for experimental studies of cancer therapy. Adv Cancer Res 27:149-200

Irwin M, Hauger RL, Brown M, Britton KT (1988): CRF activates autonomic nervous system and reduces natural killer cell cytotoxicity. Am J Physiol 255:R744-747

Irwin M, Jones L, Britton K, Hauger RL (1989): Central corticotropin releasing factor reduces natural cytotoxicity: Time course of action. Neuropsychopharmacology 2: 281-284

Irwin M, Hauger RL, Jones L, Provencio M, Britton KT (1990): Sympathetic nervous system mediates central corticotropin-release factor induced suppression of natural killer cell cytotoxicity. J Pharmacol Exp Ther 255:101-107

Karre K, Klein GO, Kiessling R, Klein G, Roder JC (1980): Low natural in vivo resistance to syngeneic leukemias in natural killer-deficient mice. Nature (Lond) 284: 624-626

Kiessling R, Wigzell (1979): An analysis of the murine NK cell as to structure, function and biological relevance. Immunol Rev 44:165-208

Kiessling R, Petranyi G, Klein G, Wigzell H (1975): Genetic variation of in vitro cytolytic activity and in vivo rejection potential in nonimmunized semi-syngeneic mice against a mouse lymphoma line. Int J Cancer 15:933-940

Kilts CD, Anderson CM, Ely TD, Mailman RB (1988): The biochemistry and pharmacology of mesoamygdaloid dopamine neurons. Ann NY Acad Sci 537:173-187

LeMoal M, Simon H (1991): Mesocorticolimbic dopaminergic network: Functional and regulatory roles. Physiol Rev 71:155-234

Lewis MH, Devaud LL, Gariepy J-L, Southerland S, Mailman RB, Cairns RB (1992): Dopamine and social behavior in mice bred for high and low levels of aggression. Brain Res Bull (in press)

Lister RG (1987): The use of a plus-maze to measure anxiety in the mouse. Psychopharmacology 92:180-185

Morley JE, Kay NE, Solomon GF, Plotnikoff NP (1987): Neuropeptides: Conductors of the immune orchestra. Life Sci 41:527-544

Petitto JM, Skolnick P, Arora PK (1989): Suppression of natural killer cell activity by FG 7142, a benzodiazepine receptor "inverse agonist." Brain Behav Immun 3:39-46

Petitto JM, McIntyre TD, McRae BL, Skolnick P, Arora PK 
(1990): Differential immune responsiveness in mouse lines selectively bred for high and low sensitivity to ethanol. Brain Behav Immun 4:39-49

Petranyi GG, Kiessling R, Klein G (1975): Genetic control of natural killer lymphocytes in the mouse. Immunogenetics 2:53-61

Reynolds CW, Holden HT (1982): Genetic variation in natural killer (NK) activity in the rat. In Herberman RB (ed), NK Cells and Other Natural Effector Cells. London, Academic Press, pp 319-324

Rosenberg SA, Spiess P, Lafrenniere R (1986): A new approach toadoptive immunotherapy of cancer with tumorinfiltrating lymphocytes. Science (Wash, DC) 233:13181321

Solomon GF (1987): Psychoneuroimmunology: Interactions between central nervous system and immune system. J Neurosci Res 18:1-9

Stein M, Miller AH, Trestman RL (1991): Depression, the immune system, and health and illness. Arch Gen Psychiatry 48:171-177
Stutman O (1973): Immunological aspects of resistance to the oncogenic effect of methylcholanthrene in mice. Isr J Med Sci 9:217-228

Stutman O, Lattime EC (1981): Natural cell-mediated cytotoxicity against tumors in mice: An heterogeneous system. Transplant Proc 13:752-755

Talmadge JE, Meyers KM, Prieur DJ, Starkey JR (1980): Role of NK cells in tumour growth and metastasis in beige mice. Nature (Lond) 284:622-624

Tecoma E, Huey L (1984): Psychic distress and the immune response. Life Sci 36:1799-1812

Trinchieri G (1989): Biology of natural killer cells. Adv Immunol 47:187-376

Unanue ER, Benacerraf B (1984): Textbook of Immunology, Waverly Press, Baltimore

Wellisch DK, Yager J (1983): Is there a cancer-prone personality? CA 33:145-153

Welsh RM (1988): Natural killer cells and interferon. Crit Rev Immunol 5:55-93 